\title{
Development and validation of a new simple Healthy Meal Index for canteen meals
}

\author{
Anne D Lassen ${ }^{1, *}$, Anja Biltoft-Jensen ${ }^{1}$, Gitte L Hansen ${ }^{2}, \mathrm{Ole} \mathrm{Hels}^{1}$ and Inge Tetens ${ }^{1}$ \\ 'Department of Nutrition, National Food Institute, Technical University of Denmark, Mørkhøj Bygade 19, DK-2860 \\ Søborg, Denmark: ${ }^{2}$ The Danish Cancer Society, Strandboulevarden 49, DK-2100 Copenhagen, Denmark
}

Submitted 20 July 2009: Accepted 23 November 2009: First published online 26 January 2010

\begin{abstract}
Objective: Nutrition evaluation tools should be developed both for scientific purposes and to encourage and facilitate healthy nutritional practices. The purpose of the present study was to develop and validate a simple food-based Healthy Meal Index (HMI) reflecting the nutritional profile of individual canteen meals.

Design: The development process included overall model selection, setting nutritional goals and defining scoring systems and thresholds. Three index components were included: (i) contents of fruit and vegetables, (ii) fat content and quality and (iii) contents of wholegrain products and potatoes. The development was built on the principles embodied by the Plate Model, but providing more specificity in some areas. The simple HMI was validated against weighed and chemically analysed food and nutrient content of a representative sample of canteen meals. The sample was split into four categories according to the total index score and compared across categories.

Setting: A total of 180 meals from fifteen worksite canteens.

Results: Average energy density decreased significantly across categories (from $876 \mathrm{~kJ} / 100 \mathrm{~g}$ to $537 \mathrm{~kJ} / 100 \mathrm{~g}, P<0 \cdot 001$ ). Also, the content of total and saturated fat, carbohydrate and fruit and vegetables varied across categories with higher score values being closer to dietary guidelines $(P<0 \cdot 001)$.

Conclusions: The simple HMI was successful in ranking canteen meals according to their nutritional quality. The index provides a valuable tool to both researchers and food and nutrition professionals, e.g. caterers and dietitians, who wish to evaluate nutritional quality of meals in line with the recommendations for healthier eating without the use of nutrition calculation programs.
\end{abstract}

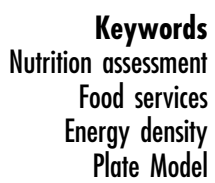

A growing body of evidence suggests that the worksite environment can have an important impact on employees' food choice and eating habits ${ }^{(1-3)}$. Besides supplying lunch and breakfast at the worksite, the take-away option from the worksite canteen is also growing in popularity among employees in Western countries ${ }^{(4)}$. It, therefore, becomes increasingly pertinent to take the worksite environment into account when designing new strategies for improving dietary behaviour among the working population.

Several policy papers, including the EU White Paper on Nutrition and the Nordic Plan of Action on Health, Food and Physical Activity, call for action to be taken at the worksites $^{(5,6)}$. Different strategies are suggested, including worksites subsidising healthy meals, offering free fruit and/or creating opportunities for physical activity ${ }^{(6)}$. To evaluate the effectiveness of the various strategies, simple and valid monitoring tools are needed ${ }^{(7-10)}$.

A variety of indexes and scores have been developed to evaluate either overall diet quality ${ }^{(11-13)}$ or overall nutrient quality of foods using the nutrient profiling approach ${ }^{(14-18)}$ However, research on indicators of nutrient quality of whole meals, including canteen meals, remains limited. Recommendations and evaluations referring to the whole diet or individual foodstuffs may be difficult to translate by caterers and consumers into daily meal planning and practice. Development of a simple meal evaluation tool could encourage caterers to self-monitor and optimise the nutritional quality of the meals offered to their customers ${ }^{(19,20)}$. Self-monitoring has been shown to be a predictor of successful dietary change and maintenance ${ }^{(21)}$. Similarly, an intervention among five canteens based on self-monitoring and empowerment resulted in significant increases in fruit and vegetable consumption ${ }^{(2)}$.

One of the nutritional challenges to be addressed in the Western countries is to lower the energy density of meals ${ }^{(22)}$. The Second Expert Report from the World Cancer Research Fund and the American Institute for Cancer Research recommend the average energy density 
of diets to be lowered from the current around $770 \mathrm{~kJ} /$ $100 \mathrm{~g}(185 \mathrm{kcal} / 100 \mathrm{~g})^{(23)}$ towards $520 \mathrm{~kJ} / 100 \mathrm{~g}(125 \mathrm{kcal} /$ $100 \mathrm{~g})$ excluding drinks to prevent and control overweight and obesity ${ }^{(24)}$. Generally, foods low in energy density are low-fat and/or water-rich foods, such as fruit, vegetables and wholegrain products ${ }^{(25)}$.

The purpose of the present study was to develop a simple Healthy Meal Index (HMI) reflecting the nutritional profile of single meals and to validate it against the measured nutrient content of a representative sample of canteen meals.

\section{Material and methods}

\section{Development of the simple HMI}

The development process is illustrated in Fig. 1. First, meetings were held with stakeholders (i.e. canteen managers, food service operators and food and nutrition professionals) to identify needs and requirements for developing the overall model of a simple HMI. Second, components to be included in the simple HMI were prioritised and nutritional goals were established for each of the components. Third, specific main and intermediate criteria and thresholds for each component goal were determined; and fourth, a validity testing of the index was carried out. Validity was examined qualitatively in terms of how well the nutritional goals corresponded with Danish Food and Nutrient recommendations ${ }^{(26-28)}$, MyPyramid from the US Department of Agriculture ${ }^{(13)}$, and by proportions illustrated by the Plate Model $^{(29,30)}$. Furthermore, to explore the effects of the simple HMI on nutrient and food content, the HMI was applied to a study sample consisting of 180 canteen meals. The sample was split into four almost equal-sized categories according to the total index score: the 'least healthy', the 'less healthy', the 'healthy' and the 'most healthy' categories. Finally, the validity of the fat content and quality component score were examined by comparison with the analysed fat contents in terms of the percentage of energy from both total and saturated fat.

\section{Study sample}

The study sample consisted of 180 canteen meals, collected at fifteen randomly chosen Danish worksite canteens. Laboratory technicians observed twelve randomly chosen customers at each worksite canteen (on two different days) and collected identically double portions of the customers' self-selected meals. The collection procedure is described in more detail elsewhere ${ }^{(3)}$. The laboratory technicians asked the customers to provide basic demographic data about themselves in terms of gender, age, weight, height and employment. Food items of all double-portion meals were weighed separately, and the portions were individually mixed and homogenised. Contents of protein, fat and ash were analysed for the 180 meals according to the procedures given by the Nordic Committee on Food Analy$\mathrm{sis}^{(31-33)}$. Dry matter content was determined by drying in a vacuum oven at $70^{\circ} \mathrm{C}$ to constant weight. Carbohydrate and energy contents were calculated from the contents of dry matter, protein, fat and ash $^{(34)}$. Recipes, product specification and methods for meal preparation were provided by the staff of the worksite canteens.

\section{Statistical analysis}

All statistical analysis was performed with Statistical Package for the Social Sciences statistical software package version 13 (SPSS Inc., Chicago, IL, USA). Continuous outcome data were compared using one-way ANOVA, if distributed normally, i.e. age, portion size, protein (E\%), total fat (E \%) and saturated fat (E \%), followed by Tukey's post hoc test to assess the differences among the categories. The Kruskal-Wallis test was used when data were skewed followed by the Mann-Whitney post hoc test. The $\chi^{2}$ test was used to compare discrete data variables,

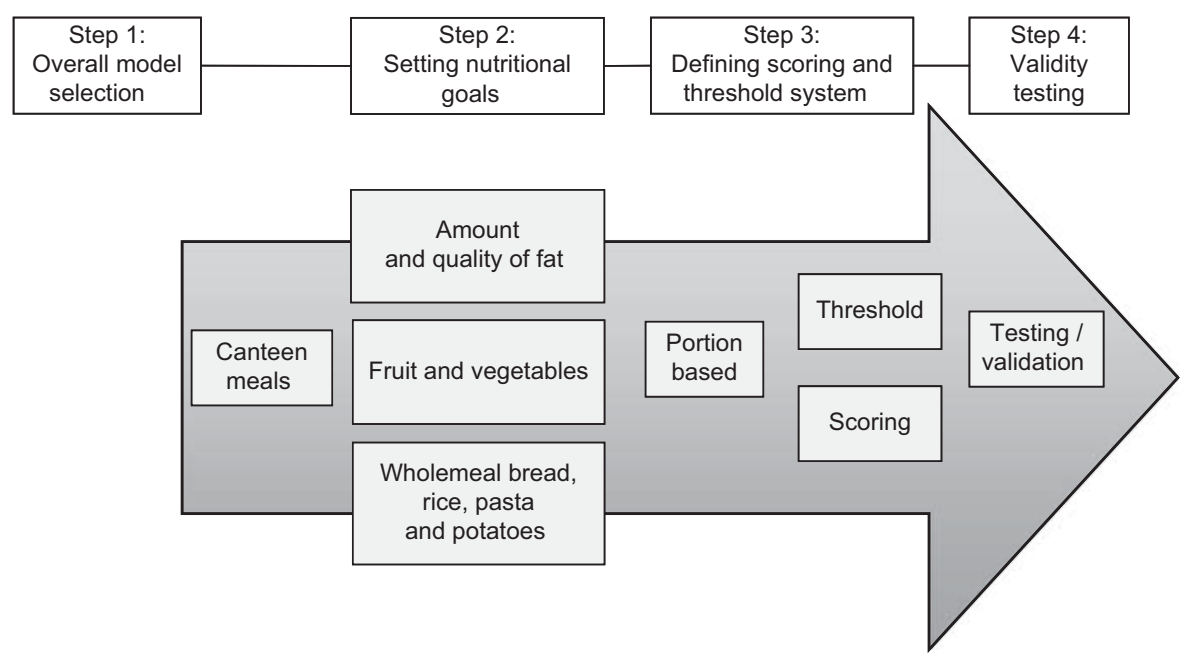

Fig. 1 Development and validation of the simple Healthy Meal Index following the nutrient profiling approach. Modified from Verhagen and van den Berg ${ }^{(46)}$ 
i.e. sex distribution and prevalence of white-collar employees. The Pearson correlation coefficient was used to assess the linear relationship between the log-transformed calculated number of fat $v$. starch units and total fat (E\%), as well as the relationship between the fat content and quality score and both total and saturated fat (E \%). $P<0.05$ was considered statistically significant.

\section{Results}

\section{Step 1: Overall model selection}

The following main requirements for developing an HMI were identified: The index should follow food and nutrient recommendations, be simple and easy to implement without the use of nutrient-calculation software, yet sensitive enough to measure relevant differences. In addition, the index should offer a visual meal-planning approach communicating proportion and balance of the meals, and also be flexible with regard to different types of meals and serving sizes. Finally, the index should be innovative, i.e. encourage caterers to make stepwise progress towards the nutritional goals. It was suggested to build the index on the principles embodied by the Plate Model, originally promoted by the Swedish Diabetic Association ${ }^{(29,30)}$, but providing more specificity in some areas, i.e. indicators of fat content and quality, as well as wholegrain content.

\section{Step 2: Setting nutritional goals}

Three key components were prioritised to be included in the simple HMI: (i) fruits and vegetables (exclusive potatoes), (ii) total fat and fat quality and (iii) wholegrain and potatoes, all components being associated with energy density and among the key measures to combat chronic diseases. Wholegrain and potatoes are combined in the same score as potatoes (cooked, baked or mashed) are common as accompaniment to hot meals with most Danes as an alternative to rice or pasta, and it is recommended to eat many potatoes (at least $150 \mathrm{~g} / \mathrm{d}$ ) ${ }^{(27)}$. The nutritional goals were defined as summarised in Table 1. For comparison, Table 1 also shows the general Danish food and nutrient recommendations, as well as the MyPyramid scaled proportionally to the content of one meal $(2-2.5 \mathrm{MJ})$, and the proportions illustrated by the Plate Mode. Although communicated very differently, good agreement was seen when converting the different recommendations to common serving quantities and goals for individual meals.

\section{Step 3: Defining scoring systems and thresbolds}

Scoring systems and thresholds for each index component were defined as summarised in Table 2. The following scoring system was chosen: zero point corresponds to the lowest dietary quality, one point to medium and two points to maximum dietary quality. The scores for these individual components were summed to determine the overall score for the simple HMI. The specified cut-offs described in Table 2 were used to assign points.

Unit sizes were defined by household measures, such as slices, cups and pieces. For validation purposes, weights in grams were assigned to each of the units. One unit of fruit and vegetables corresponds to minimum $75 \mathrm{~g}$ fruits and vegetables. One unit of wholegrain/potato

Table 1 Nutritional goals as defined for the simple Healthy Meal Index and comparison with recommended intake and proportions illustrated by the Plate Model

\begin{tabular}{|c|c|c|c|c|}
\hline $\begin{array}{l}\text { Healthy Meal Index } \\
\text { components }\end{array}$ & $\begin{array}{l}\text { Danish food and nutrient } \\
\text { recommendations }\end{array}$ & $\begin{array}{l}\text { MyPyramid scaled } \\
\text { proportionally to } 2-2.5 \mathrm{MJ}^{*}\end{array}$ & Plate Modelt & $\begin{array}{l}\text { Healthy Meal Index: nutritional } \\
\text { goals }\end{array}$ \\
\hline $\begin{array}{l}\text { Fruits and } \\
\text { vegetables }\end{array}$ & $\begin{array}{l}\text { - } 600 \mathrm{~g} \text { fruits and } \\
\text { vegetables per } \mathrm{d} \\
\text { (excluding potatoes) } \ddagger \\
\text { - } 150 \mathrm{~g} \text { per canteen meal§ }\end{array}$ & $\begin{array}{l}\text { About one cup of raw or } \\
\text { cooked fruits and } \\
\text { vegetables, or two cups } \\
\text { of leafy salad green }\end{array}$ & $\begin{array}{l}40 \% \text { of the plate } \\
(\sim 150 \mathrm{~g})\end{array}$ & $\begin{array}{l}\text { Minimum } 150 \mathrm{~g} \text { vegetables } \\
\text { and/or fruits per meal } \\
\text { (excluding potatoes) }\end{array}$ \\
\hline $\begin{array}{l}\text { Fat content and } \\
\text { quality }\end{array}$ & $\begin{array}{l}\text { - Population goal is } 30 \% \text { of } \\
\text { energy from fatll } \\
\text { - Saturated plus trans fatty } \\
\text { acids should be limited to } \\
10 \% \text { or lower of the total } \\
\text { energyll }\end{array}$ & $\begin{array}{l}6 \mathrm{~g} \text { oil plus discretionary } \\
\text { energy allowance }\end{array}$ & $\begin{array}{l}\text { Protein sources and } \\
\text { fats: } 20 \% \text { of the plate } \\
(\sim 75 \mathrm{~g})\end{array}$ & $\begin{array}{l}\text { Maximum } 30 \% \text { of energy from } \\
\text { fat in meals and preferably } \\
\text { fat of vegetable origin }\end{array}$ \\
\hline $\begin{array}{l}\text { Wholegrain and } \\
\text { potatoes }\end{array}$ & $\begin{array}{l}\text { - } 75 \mathrm{~g} \text { wholegrain per } \\
10 \mathrm{MJ} \Phi \\
\text { - Potatoes at least four } \\
\text { times a week }(\sim 150 \mathrm{~g} / \mathrm{d}) \ddagger\end{array}$ & $\begin{array}{l}\text { About half cup of cooked } \\
\text { wholegrain rice/pasta or } \\
\text { one slice of wholegrain } \\
\text { bread and half cup of } \\
\text { cooked refined grain } \\
\text { rice/pasta or one slice of } \\
\text { bread }\end{array}$ & $\begin{array}{l}\text { Bread, rice, pasta, } \\
\text { potatoes: } 40 \% \text { of the } \\
\text { plate }(\sim 150 \mathrm{~g} ; \\
\text { wholegrain amount } \\
\text { not specified) }\end{array}$ & $\begin{array}{l}\text { Minimum } 50-75 \mathrm{~g} \text { wholegrain } \\
\text { bread, cooked rice or pasta } \\
\text { per meal (corresponds to } \\
\text { approximately } 15-25 \mathrm{~g} \\
\text { wholegrain) or } 150 \mathrm{~g} \\
\text { potatoes }\end{array}$ \\
\hline
\end{tabular}

*USDA food guidance system ${ }^{(12)}$.

tAdapted from the British Dietetic Association ${ }^{(30)}$; the plate is divided into three sections (like a ' $Y$ '). Although the Plate Model is a visual model, an estimated average portion size of each component was estimated from total average lunch canteen weight (i.e. $360 \mathrm{~g}$; adapted from Lassen et al. ${ }^{(3)}$ ).

$\neq$ Danish Food-Based Dietary Guidelines ${ }^{(26,27)}$

§Danish Canteen Nutrition Guidelines (in Danish: http://www.altomkost.dk).

IINordic Nutrition Recommendations ${ }^{(28)}$.

Danish dietary recommendation for the intake of wholegrain ${ }^{(27)}$ 
corresponds to minimum $75 \mathrm{~g}$ wholegrain pasta or rice, $50 \mathrm{~g}$ wholegrain bread or $150 \mathrm{~g}$ potatoes. With regard to the fat content and quality component, number of fat units was combined with number of starchy food units as a measure of the relative content of fat. Number of fat units was subtracted from the number of starchy food units, and rounded to the nearest whole number. Positive values were assigned two points, whereas negative values were assigned zero points. In the case of equal amount of fat and starchy units, either one or two points were assigned depending on the fat quality as described in Table 2 .

Fat units were defined as equivalent to $5 \mathrm{~g}$ of fat, and all fat-containing products were categorised into the following main groupings to simplify the measure: low-fat products (e.g. ham lean, cottage cheese; $5 \%$ fat or less), medium-fat products (e.g. chicken with skin, whole egg; approximately $10 \%$ fat), high-fat products (e.g. liver pate, sausage, feta cheese; approximately $25 \%$ fat), very highfat products (e.g. bacon, pepperoni, regular vinegar/oil salad dressing; approximately $50 \%$ fat) and solid fats and oils (e.g. butter, oil, mayonnaise; approximately $80 \%$ or more fat). Fish and plain nuts were not counted as fat units regardless of fat content, as these foods are considered a part of a healthy diet. The starch food units included low-fat starchy products, whereas sweets, such as cakes, were excluded. One starch unit corresponds to an energy content of about $400-500 \mathrm{~kJ}$ (not shown).

\section{Step 4: Validity testing}

No significant differences were found with respect to the tested background variables (i.e. age, sex distribution, prevalence of white-collar employees and BMI) over the four HMI categories. The study population ( $n$ 180) included 39\% women and 62\% white-collar workers. Average age was 40 (SD 9) years and average BMI was $24 \cdot 6(\mathrm{sD} 3 \cdot 7) \mathrm{kg} / \mathrm{m}^{2}$.

Food and nutrient content by HMI categories is shown in Table 3. Energy density as well as the content of total fat, saturated fat, carbohydrate and fruit and vegetables were all highly significant across categories $(P<0 \cdot 001)$ with higher scores being closer to dietary guidelines. In addition, higher scores were significantly connected to bigger portion sizes $(P=0 \cdot 049)$. As regards wholegrain content only the 'least healthy' category differed significantly from the other categories $(P=0 \cdot 03)$.

Figure 2 examines the fat content and quality component. As shown in Fig. 2a, the calculated amount of fat units compared to starchy food units (log-transformed) correlated well with the measured percentage of energy from fat $(r=0 \cdot 85)$. Figure $2 \mathrm{~b}$ shows that the allocation of points for the fat content and quality component also seemed to correlate well with both the measured total and saturated fat contents expressed as a percentage of energy $(r=0.82$ and 0.65 , respectively). Mean values were $43 \%$, $29 \%$ and $20 \%$ of energy from fat for meals allocated zero, one or two points, respectively. Corresponding mean 
Table 3 Nutrient and food content of fifteen canteens' meals categorised into quartiles according to the simple Healthy Meal Index total scores

\begin{tabular}{|c|c|c|c|c|c|c|c|c|c|}
\hline & \multicolumn{2}{|c|}{$\begin{array}{c}\text { 'Least healthy' category } \\
\text { Score: } 0-1 \\
(n \text { 38) }\end{array}$} & \multicolumn{2}{|c|}{$\begin{array}{c}\text { 'Less healthy' category } \\
\text { Score: } 2 \\
(n 52)\end{array}$} & \multicolumn{2}{|c|}{$\begin{array}{c}\text { 'Healthy' category } \\
\text { Score: } 3 \\
(n 45)\end{array}$} & \multicolumn{2}{|c|}{$\begin{array}{c}\text { 'Most healthy' category } \\
\text { Score: 4-6 } \\
(n \text { 45) }\end{array}$} & \multirow[b]{2}{*}{$P$-value } \\
\hline & Mean & SE & Mean & SE & Mean & SE & Mean & $\mathrm{SE}$ & \\
\hline Energy density $(\mathrm{kJ} / 100 \mathrm{~g})$ & $876^{a}$ & 42 & $722^{b}$ & 32 & $640^{\mathrm{b}}$ & 20 & $537^{c}$ & 21 & $<0.001$ \\
\hline Energy (MJ/meal) & $2 \cdot 6$ & 1.9 & $2 \cdot 5$ & $1 \cdot 4$ & $2 \cdot 4$ & 0.1 & $2 \cdot 1$ & $0 \cdot 1$ & 0.052 \\
\hline Portion size (g/meal) & $317^{\mathrm{a}}$ & 25 & $353^{a b}$ & 15 & $375^{\mathrm{ab}}$ & 18 & $389^{\mathrm{b}}$ & 17 & 0.049 \\
\hline Carbohydrate (E \%) & $40^{\mathrm{a}}$ & 1 & $40^{\mathrm{a}}$ & 2 & $46^{\mathrm{b}}$ & 2 & $55^{\mathrm{c}}$ & 2 & $<0.001$ \\
\hline Protein (E \%) & 18 & 1 & 19 & 1 & 21 & 1 & 20 & 1 & 0.27 \\
\hline Fat $(\mathrm{E} \%)$ & $42^{\mathrm{a}}$ & 1 & $41^{\mathrm{a}}$ & 2 & $33^{\mathrm{b}}$ & 2 & $25^{\mathrm{c}}$ & 1 & $<0.001$ \\
\hline Saturated fat $(\mathrm{E} \%)$ & $13^{a}$ & 1 & $11^{\mathrm{ab}}$ & 1 & $9^{b c}$ & 1 & $7^{c}$ & 1 & $<0.001$ \\
\hline Fat $(g /$ meal $)$ & $29^{\mathrm{a}}$ & 2 & $27^{\mathrm{a}}$ & 2 & $22^{b}$ & 2 & $15^{\mathrm{c}}$ & 2 & $<0.001$ \\
\hline Saturated fatty acids (g/meal) & $9^{a}$ & 1 & $8^{a b}$ & 1 & $6^{b}$ & 1 & $4^{\mathrm{c}}$ & 1 & $<0.001$ \\
\hline Vegetables and fruit $(\mathrm{g} / \mathrm{meal})^{*}$ & $49^{a}$ & 7 & $97^{\mathrm{b}}$ & 11 & $127^{\mathrm{c}}$ & 9 & $200^{\mathrm{d}}$ & 16 & $<0.001$ \\
\hline Wholegrain $(\mathrm{g} / \mathrm{meal}) \dagger$ & $3^{a}$ & 1 & $8^{\mathrm{b}}$ & 2 & $9^{b}$ & 1 & $8^{\mathrm{b}}$ & 2 & 0.03 \\
\hline
\end{tabular}

$E \%$, percentage of food energy.

$\mathrm{a}, \mathrm{b}, \mathrm{c}, \mathrm{d}$ Values within a row with different superscript letters are significantly different $(P<0.05)$.

${ }^{*}$ Excluding potatoes.

tCalculated from the amount of wholegrain bread, rice and pasta.
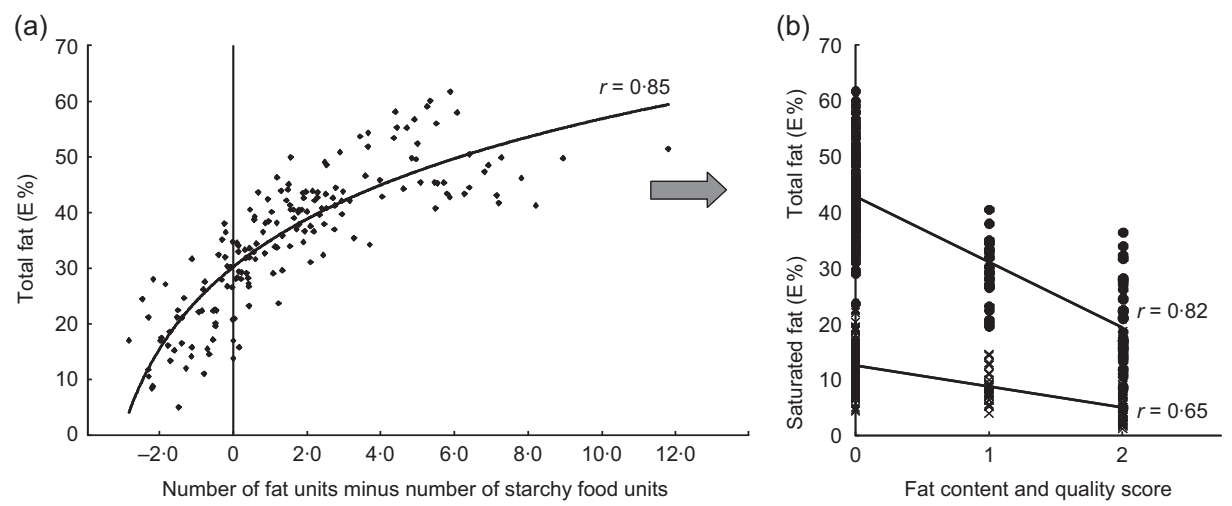

Fig. 2 Examination of the fat content and quality component score. (a) Calculated number of fat minus starchy food units compared with the percentage energy $(E \%)$ from the total fat. (b) Allocation of point (based on the calculated number and whether the fat is mainly of animal or vegetable origin) compared with the percentage energy $(E \%)$ from the total fat $(\mathbf{O})$ and saturated fat $(\mathbf{X})$, respectively $(n$ 180)

values for the percentage of energy from saturated fat were 13,9 and 5 (not shown).

\section{Discussion}

The HMI was developed as a simple food-based method for evaluating the nutritional quality of canteen meals based on three components and three levels of component scores. The first component measures compliance with recommendation for fruit and vegetables; the second component measures compliance with respect to fat content and quality; and the final component measures compliance with respect to the contents of wholegrain cereals and potatoes. Our findings indicate that the simple HMI is a valid estimate of overall diet quality of canteen meals. Increasing index scores were significantly associated with decreasing energy density, contents of energy, total fat, saturated fat and carbohydrate, and with increasing portion size and content of fruit and vegetables in the 180 canteen meals tested.
Mean energy density of the canteen meals differed from around $880 \mathrm{~kJ} / 100 \mathrm{~g}$ in the least healthy category to around $540 \mathrm{~kJ} / 100 \mathrm{~g}$ in the most healthy category, thereby equalling the energy density recommended by the World Cancer Research Fund and the American Institute for Cancer Research ${ }^{(24)}$. The recommendation is mainly intended to prevent excess energy intake. In addition, lower energy density seems to be connected to increased nutrient density and overall diet quality ${ }^{(35)}$. In the present sample of canteen meals, the energy content of the meals in the healthiest category, as defined by the simple HMI, was about $20 \%$ lower than those in the least healthy category. This is in line with differences in the total daily energy intake found by Biltoft-Jensen et al. ${ }^{(11)}$ between compliers and non-compliers identified by the simple dietary quality index and by Schröder et al. ${ }^{(35)}$ between subjects eating diets differing in overall energy density.

The present HMI was developed to assist caterers in making healthy meal offers without having to use nutrient-calculation software. The catering industry has an 
important responsibility to provide nutritious food to the consumers, but also to influence perceived norms regarding eating behaviour ${ }^{(4,36)}$. However, caterers must also deal with the practical realities of limited resources $^{(37)}$, and therefore have neither the time nor the skills to make complicated calculations ${ }^{(38)}$. In addition, there seems to be a widespread confusion among caterers over what constitutes healthy meals ${ }^{(39,40)}$.

The limitations of the simple HMI should be noted. The index involves counting food ingredients from mixed dishes, which is a common challenge when assessing dietary intake ${ }^{(41)}$. It needs to be combined with recipe, product specification and menu preparation reviews. The contents of the nutrients, on the other hand, were chemically analysed, which is considered to give the most reliable results ${ }^{(38)}$. Beverages were not included in the study, as the focus was on meals provided by the caterers, and the relationship between energy density and macronutrient content and beverages is more complex than that of individual foods or meals ${ }^{(42)}$. Beverages, however, may contribute significantly to the total energy intake. In addition, the index does not deal with all aspects of nutritional recommendations, and reliable indicators of, for example, salt content should be developed and tested for future extension of the simple HMI.

A major strength of the simple HMI is that it is designed to measure and communicate the proportion of foods based on an understanding through visual messages according to the Plate Model. It may therefore provide a bridge between scientific research and communication. The Plate Model has been found to be the preferred educational nutrition model by both professionals and the public $^{(43)}$, and meal components may be selected to match a range of different meal types and preferences. However, paradoxically, the simplicity has been seen as a disadvantage by some, who expect a more complex approach to meal planning ${ }^{(44)}$. The present HMI provides more specificity to the Plate Model, introducing the concept of fat units to evaluate fat content and quality. The basic idea of the fat content and quality score being that there is room for one fat unit, preferably of vegetable origin (equalling $5 \mathrm{~g}$ fat) per starchy food unit. For example, one piece of bread with a thin layer of butter is assigned one point (due to animal origin), an open sandwich with some mayonnaise is assigned two points (due to vegetable origin), whereas an open sandwich with both butter and mayonnaise results in zero points. Fat and fatty products are categorised into main groups to simplify the counting of fat units. The fat content and quality component score was found to correlate well with the measured percentage of energy from total $(r=0 \cdot 82)$ and saturated fat $(r=0 \cdot 65)$.

The uses of the simple HMI may be multiple. In addition to being used in the catering sector as a selfassessment tool for nutritional quality control, the index could be used as a valid measure of the nutritional quality of meals consumed elsewhere, including take-away dinners and home dinner meals. The canteen meals in the present study represented a great variety of meal types, including hot and cold meals (open as well as closed sandwiches), salads and buffet-style combinations. The total and each component scores separately may be used as tools for nutritional quality control of the meals. In addition, food and nutrition professionals may use the index in counselling clients how to modify meals to meet dietary goals. For research purposes, the simple HMI could be used in combination with the digital photography method ${ }^{(45)}$ to evaluate a representative sample of an employee's food selection, and thereby provide an overall picture of the nutritional eating environment. The nutritional profile of what was eaten is largely determined by what is offered as found by Lachat et al. ${ }^{(8)}$ in a Belgian university canteen.

\section{Conclusion}

In conclusion, the present paper introduces a novel concept for evaluating the nutritional quality of individual meals. The simple HMI successfully ranked canteen meals according to their nutritional quality. It has implications for both research and practice, and provides a valuable tool to both professionals, e.g. caterers and dietitians, and the general public who wish to evaluate nutritional quality of meals in line with the recommendations for healthy eating without the use of nutrition calculation programs.

\section{Acknowledgements}

The project is part of the Canteen Take Away Study funded by the Danish Council for Strategic Research, a programme for health, food and welfare. The authors declare no conflict of interest. All the authors contributed to the study concept and design, interpretation of data and preparation of the manuscript. O.H. contributed to the statistical analysis of the data. The authors thank all who took part in the survey. They also thank Lars Ovesen from Slagelse Hospital, Department of Gastroenterology, and Marianne Sabinsky, Anne Marie Bech and Anne Vibeke Thorsen from DTU National Food Institute for their advice and manuscript review.

\section{References}

1. Buttriss J, Stanner S, McKevith AP et al. (2004) Successful ways to modify food choice: lessons from the literature. Nutr Bull 29, 333-343.

2. Lassen A, Thorsen AV, Trolle E et al. (2004) Successful strategies to increase the consumption of fruits and vegetables: results from the Danish ' 6 a day' Work-site Canteen Model Study. Public Health Nutr 7, 263-270.

3. Lassen A, Hansen K \& Trolle E (2007) Comparison of buffet and a la carte serving at worksite canteens on nutrient intake and fruit and vegetable consumption. Public Health Nutr 10, 292-297. 
4. Wanjek C (2005) Food at Work: Workplace Solutions for Malnutrition, Obesity and Chronic Diseases. Switzerland: International Labour Organisation.

5. European Commission (2007) White Paper on a Strategy for Europe on Nutrition, Overweight and Obesity Related Health Issues. ENVI/6/50465. Brussels: European Commission.

6. Nordic Council of Ministers (2006) Health, Food and Physical Activity - Nordic Plan of Action on Better Health and Quality of Life through Diet and Physical Activity. Copenhagen: Nordic Council of Ministers.

7. WHO Regional Office for Europe (2007) Second WHO European Action Plan for Food and Nutrition Policy 2007-2012. Copenhagen: WHO Regional Office for Europe.

8. Lachat C, Roberfroid D, Huybregts L et al. (2009) Incorporating the catering sector in nutrition policies of WHO European Region: is there a good recipe? Public Health Nutr 12, 316-324.

9. Elinder SL \& Jansson M (2009) Obesogenic environments aspects on measurement and indicators. Public Health Nutr 12, 307-315.

10. Veiros MB, Proenca RPC, Kent-Smith L et al. (2006) How to analyse and develop healthy menus in food service. J Foodserv 12, 307-315.

11. Biltoft-Jensen A, Fagt S, Groth MV et al. (2008) The intake of saturated fat and dietary fibre: a possible indicator of diet quality. Br J Nutr 100, 624-632.

12. Britten P, Marcoe K, Yamini S et al. (2006) Development of food intake patterns for the MyPyramid Food Guidance System. I Nutr Educ Behav 38, S78-S92.

13. Guenther PM, Reedy J \& Krebs-Smith SM (2008) Development of the Healthy Eating Index-2005. I Am Diet Assoc 108, 1896-1901.

14. University of Crete School of Medicine (2000) Eurodiet Core Report, nutrition \& diet for healthy lifestyles in Europe Science \& policy implications. Public Health Nutr 4, 265-273.

15. Drewnowski A, Maillot M \& Darmon N (2009) Testing nutrient profile models in relation to energy density and energy cost. Eur J Clin Nutr 63, 674-683.

16. Drewnowski A, Fulgoni VL, Young MK et al. (2008) Nutrient-rich foods: applying nutrient navigation systems to improve public health. J Food Sci 73, H222-H228.

17. Tetens I, Oberdorfer R, Madsen C et al. (2007) Nutritional characterisation of foods: science-based approach to nutrient profiling. Summary report of an ILSI Europe workshop held in April 2006. Eur J Nutr 46, Suppl. 2, 4-14.

18. Mejborn H, Biltoft-Jensen A, Ygil KH et al. (2009) Development of A Valid, Yet Simple and Easy Nutrition Profiling Model. Copenhagen: Technical University of Denmark, National Food Institute.

19. Benjamin SE, Neelon B, Ball SC et al. (2007) Reliability and validity of a nutrition and physical activity environmental selfassessment for child care. Int J Behav Nutr Phys Act 4, 29.

20. Brug J, Oenema A \& Ferreira I (2005) Theory, evidence and intervention mapping to improve behavior nutrition and physical activity interventions. Int J Behav Nutr Phys Act 2, 2.

21. Tinker LF, Rosal MC, Young AF et al. (2007) Predictors of dietary change and maintenance in the Women's Health Initiative Dietary Modification Trial. I Am Diet Assoc 107, 1155-1166.

22. World Health Organization (2003) Diet, Nutrition and the Prevention of Chronic Diseases. Report of the WHO/FAO Joint Expert Consultation WHO Technical Report Series no. 916. Geneva: WHO.

23. Ledikwe JH, Blanck HM, Khan LK et al. (2005) Dietary energy density determined by eight calculation methods in a nationally representative United States population. J Nutr 135, 273-278.

24. World Cancer Research Fund/American Institute for Cancer Research (2007) Food, Nutrition, Physical Activity, and the Prevention of Cancer: A Global Perspective. Washington, DC: AICR.
25. Astrup A (2008) Dietary management of obesity. JPEN J Parenter Enteral Nutr 32, 575-577.

26. Astrup A, Andersen NL, Stender S et al. (2005) Kostrådene 2005 (Dietary Guidelines 2005). Copenhagen: Danish Institute for Food and Veterinary Research and Danish Nutritional Council.

27. Mejborn H, Biltoft-Jensen A, Trolle E et al. (2008) Fuldkorn. Definition og vidensgrundlag for anbefaling af fuldkornsindtag $i$ Danmark (Wholegrain. Definition and Scientific Background for Recommendations of Wholegrain Intake in Denmark). Soeborg: Technical University of Denmark, National Food Institute.

28. Nordic Council of Ministers (2004) Nordic Nutrition Recommendations 2004. Integrating Nutrition and Physical Activity. Nord 2004:13, 4th ed. Copenhagen: Nordic Council of Ministers.

29. Karlstrom B, Vessby B \& Eliasson M (1989). Diet - a balanced approach. In Diabetes, pp. 923-925 [R Larkins, P Zimmet and D Chisholm, editors]. Amsterdam: Elsevier Science Publishers BV.

30. The British Dietetic Association (2003) The dietitians challenge: the implementation of nutritional advice for people with diabetes. J Hum Nutr Diet 16, 421-452.

31. Nordic Committee on Food Analysis (2003) Nitrogen. Determination in Foods and Feeds According to Kjeldahl. Method No. 6, 4th ed. Oslo: NKML.

32. Nordic Committee on Food Analysis (1998) Fat. Determination in foods. Method No. 160. Oslo: NKML.

33. Nordic Committee on Food Analysis (1989) Ash. Gravimetric Determination in Foods. Method no. 128. Oslo: NKML.

34. Saxholt E \& Møller A (1996) Food Composition Tables, 4th ed. (in Danish). Copenhagen: National Food Agency of Denmark.

35. Schroder H, Covas M, Elosua R et al. (2008) Diet quality and lifestyle associated with free selected low-energy density diets in a representative Spanish population. Eur J Clin Nutr 62, 1194-1200.

36. Roos E, Sarlio-Lahteenkorva S \& Lallukka T (2004) Having lunch at a staff canteen is associated with recommended food habits. Public Health Nutr 7, 53-61.

37. Glanz K, Resnicow K, Seymour J et al. (2007) How major restaurant chains plan their menus: the role of profit, demand, and health. Am J Prev Med 32, 383-388.

38. Guilland A (2001) Nutrient based quality control in public catering: need for revision. J Food Eng 56, 189-193.

39. Maddock B, Warren C \& Worsley A (2005) Survey of canteens and food services in Victorian schools. Nutr Diet 62, 76-81.

40. Stanner S (2001) Catering for health. Nutr Bull 26, 255-258.

41. Newby PK, Hu FB, Rimm EB et al. (2003) Reproducibility and validity of the Diet Quality Index revised as assessed by use of a food-frequency questionnaire. Am J Clin Nutr $\mathbf{7 8}, 941-949$.

42. Crowe TC, La Fontaine HA, Gibbons CJ et al. (2004) Energy density of foods and beverages in the Australian food supply: influence of macronutrients and comparison to dietary intake. Eur J Clin Nutr 58, 1485-1491.

43. Hunt P, Rayner M \& Gatenby S (1994) Pyramid or plate? The development of a national food guide for the UK: a preliminary article. Nutr Food Sci 94, 7-12.

44. Camelon KM, Hadell K, Jamsen PT et al. (1998) The Plate Model: a visual method of teaching meal planning. DAIS Project Group. Diabetes Atherosclerosis Intervention Study. J Am Diet Assoc 98, 1155-1158.

45. Williamson DA, Allen HR, Martin PD et al. (2004) Digital photography: a new method for estimating food intake in cafeteria settings. Eat Weight Disord 9, 24-28.

46. Verhagen H \& van den Berg H (2008) A simple visual model to compare existing nutrient profiling schemes. Food Nutr Res $\mathbf{5 2}$. 